\title{
Determination of Tylenchulus semipenetrans Biotype in Zebediela and Champagne, Republic of South Africa
}

\author{
R. G. Kwaye, P. W. Mashela, H. Shimelis, and N. Mapope, Department of Plant Production, School of Agricultural \\ and Environmental Sciences, University of Limpopo, SOVENGA 0727, Republic of South Africa
}

\begin{abstract}
Kwaye, R. G., Mashela, P. W., Shimelis, H., and Mapope, N. 2008. Determination of Tylenchulus semipenetrans biotype in Zebediela and Champagne, Republic of South Africa. Plant Dis. 92:639-641.

The biotype of the citrus nematode (Tylenchulus semipenetrans) from Zebediela and Champagne Citrus Estates, Republic of South Africa, was determined using 2-year-old differential hosts, namely, grape (Vitis vinifera cv. Richter 110), carrizo citrange (Citrus sinensis $\times$ Poncirus trifoliata), rough lemon $(C$. jambhiri), olive (Olea europaea cv. Misson), and trifoliate orange $(P$. trifoliata). The study was conducted under greenhouse conditions with 10 replicates. Nematodes from Zebediela and Champagne were extracted from roots through mechanical shaking, sieving, and incubation in Baermann trays and inoculated at 10,000 and 40,000 eggs and juveniles per plant, respectively. Results demonstrated that the citrus nematode from Zebediela had reproductive factors greater than one on grape, rough lemon, trifoliate orange, and carrizo citrange, but lower than one on olive. Reproductive factors were less than one for all differential hosts with the Champagne population, with olive having the lowest value. Differential-host tests using Zebediela and Champagne nematode populations suggested that the T. semipenetrans biotype is poncirus.
\end{abstract}

Additional keywords: citrus biotype, Mediterranean biotype

The citrus nematode (Tylenchulus semipenetrans Cobb.) inflicts significant losses in most citrus-growing areas through fruit losses and debilitation of trees $(4,5)$. Resistant rootstocks had been an option of choice in the management of population densities of this nematode $(4,12)$. However, in many instances, the existence of $T$. semipenetrans biotypes has reduced the efficacy of resistant rootstocks. Nematode biotypes are morphologically identical but have different reproductive potentials on different hosts. First evidence of $T$. semipenetrans biotypes emerged in the early 1970s (1). Four biotypes were identified first in California (1) which have since been confirmed in Florida $(6,11)$, Israel (7), Italy (10), and Spain (17).

Based on differential-host tests, the four identified biotypes are the (i) citrus, (ii) mediterranean, (iii) poncirus, and (iv) grass biotypes $(1,7,9-11,16)$. The first three biotypes share citrus as a common host but differ in their ability to infect and reproduce on trifoliate orange (Poncirus trifoliata L.) and olive (Olea europaea L.). Trifoliate orange is parasitized only by the

Corresponding author: H. Shimelis

E-mail: Shimelis@ul.ac.za

Accepted for publication 20 November 2007.

doi:10.1094/PDIS-92-4-0639

(C) 2008 The American Phytopathological Society poncirus biotype which does not infect olive, whereas the citrus biotype infects olive but not trifoliate orange (12). The mediterranean biotype reproduces very poorly on both $P$. trifoliata and olive (17).

Knowledge of the biotypes in citrusproducing regions is useful in the choice of resistant rootstocks in both breeding and production programs (9). The citrus biotype is widespread in California and Italy $(1,9)$, whereas the poncirus biotype is resident in California, Israel, Florida, and Japan $(1,6,7,9)$. The mediterranean biotype had been reported from countries in the Mediterranean basin $(7,17)$. The citrus nematode biotypes in Florida, Arizona, and Texas may be the mediterranean or citrus biotypes because they infect and reproduce poorly on $P$. trifoliata (12).

Without empirical support, Cohn (2) suggested that the $T$. semipenetrans biotype in the Republic of South Africa was the mediterranean biotype, which implied that the biotype did not reproduce on both $P$. trifoliata and olive. This assumption, cross-referenced by others $(9,12)$, resulted in widespread use of $P$. trifoliata rootstocks in the Republic of South Africa for the management of the citrus nematode. However, over the years, the use of $P$. trifoliata had declined from $21 \%$ to approximately $5 \%$ because the rootstock was unsuitable for the South African citrus industry (13). Under South African conditions, $P$. trifoliata lacked vigor and had poor tolerance to high soil $\mathrm{pH}$ and salinity
(13). The objective of this study was to determine the $T$. semipenetrans biotype in Zebediela and Champagne Citrus Estates using differential-host tests.

\section{MATERIALS AND METHODS}

The study was conducted under greenhouse conditions at the Horticultural Unit of the University of Limpopo $\left(23^{\circ} 53^{\prime \prime} 10^{\prime} \mathrm{S}\right.$, $\left.29^{\circ} 44^{\prime \prime} 15^{\prime} \mathrm{E}\right)$. Differential-host plants included approximately 2-year-old grape (Vitis vinifera L.), carizzo citrange (Citrus sinensis $\times P$. trifoliata), rough lemon $(C$. jambhiri Lush), olive, and trifoliate orange (P. trifoliata). Plant roots and tops were pruned and plants transplanted into $30-\mathrm{cm}-$ diameter plastic pots, filled with 2.8 liters of steam-pasteurized sandy soil and Hygromix (Hygrotech, South Africa) at 3:1 $(\mathrm{vol} / \mathrm{vol})$. Pots were placed on the greenhouse bench at $30-\mathrm{cm}$ interrow $\times 60-\mathrm{cm}$ intrarow spacing. Two days after transplanting, plants were fertilized with $5 \mathrm{~g}$ of 2:3:2 N:P:K (22\% active) $+0.5 \% \mathrm{Zn}$.

Zebediela and Champagne nematode populations were used in two separate experiments which ran concurrently. Populations for inoculation were obtained from citrus roots collected from 25 randomly selected healthy looking trees per hectare on rough lemon rootstocks at Zebediela $\left(24^{\circ} 11^{\prime} \mathrm{S}, 2^{\circ} 01^{\prime} \mathrm{E}\right)$ and Champagne Citrus Estates $\left(24^{\circ} 50^{\prime} \mathrm{S}, 31^{\circ} 20^{\prime} \mathrm{E}\right)$. Root samples weighing approximately $500 \mathrm{~g} /$ tree were collected, composited, and transported to the laboratory in cooler boxes. Roots were cut into small pieces, placed into $1,000-\mathrm{ml}$ bottles containing $1 \% \mathrm{NaOCl}$ solution (8), and mechanically shaken for $10 \mathrm{~min}$. Contents from bottles were passed through a $45-\mu \mathrm{m}$-pore sieve nested on a $25-\mu \mathrm{m}$-pore sieve, with contents of the latter being washed into a 250-ml beaker. Baermann trays were used to obtain second-stage juveniles (J2) for inoculation $(8,14)$.

Grape, carizzo citrange, rough lemon, olive, and trifoliate orange host plants were arranged in a randomized complete block design, with 10 replicates. Two months after transplanting, plants for Zebediela Experiment were inoculated with approximately 10,000 J2/plant. Nematodes were applied into $10-\mathrm{cm}$-deep holes on the cardinal quadrants of trunks using a 20-ml plastic syringe. Plants for Champagne Experiment were inoculated with approximately $40,000 \mathrm{~J} 2 /$ plant because preliminary studies had indicated that the Champagne population was less virulent 
than the Zebediela population (P. W. Mashela, unpublished data).

Two tensiometers per treatment were inserted 20 and $30 \mathrm{~cm}$ deep in randomly selected pots to determine the water potential of the soil. Plants were hand-irrigated with $1,000 \mathrm{ml}$ of tap water when readings averaged from 30 to $50 \mathrm{kPa}$. Ambient day temperatures in the greenhouse were maintained at 25 and $20^{\circ} \mathrm{C}$ maximum and minimum, respectively.

At harvest, 120 days after inoculation with nematodes, stems were cut at the crown and pots were emptied to remove root systems and immersed in water to free soil particles. Nematodes were separated from $20 \mathrm{~g}$ of roots per plant by maceration and blending for $30 \mathrm{~s}$ in $1 \% \mathrm{NaOCl}(8)$, then passed through a $45-\mu \mathrm{m}$-pore sieve onto a $25-\mu \mathrm{m}$-pore sieve, and contents of the latter were collected for nematode counting. Soil per pot was thoroughly mixed and a $250-\mathrm{cm}^{3}$ soil sample was collected. Nematodes were extracted from soil samples using the sugar-floatation and centrifugation method (3). Eggs and juve- niles were counted from a 10-ml aliquot with the use of a stereomicroscope.

Nematode numbers from roots were converted to nematodes per total root system per host, whereas soil nematode numbers were converted to $28,000 \mathrm{~cm}^{3}$ of soil per pot. Reproductive factors (RFs), described as final population/initial population $(\mathrm{Pf} / \mathrm{Pi})$ ratios, were subjected to analysis of variance with SAS software (SAS Institute, Cary, NC). Mean separation was achieved with Fisher's least significant difference test. In order to compare the final population densities from the two populations, initial nematode numbers from Champagne were standardized to $10,000 \mathrm{~J} 2$ and analyzed using the independent $t$ test procedure.

\section{RESULTS}

Analysis of variance for RFs of $T$. semipenetrans populations from Zebediela and Champagne Citrus Estates on differential hosts had highly significant differences (Table 1). Differential hosts explained 67 and $55 \%$ of total treatment variation in

Table 1. Analysis of variance for reproductive factor of Tylenchulus semipenetrans populations from two citrus-producing regions of South Africa based on numbers in roots and soil of differential hosts in a greenhouse experiment ${ }^{\mathrm{a}}$

\begin{tabular}{|c|c|c|c|c|c|}
\hline \multirow[b]{2}{*}{ Source of variation } & \multirow[b]{2}{*}{ df } & \multicolumn{2}{|c|}{ Zebediela } & \multicolumn{2}{|c|}{ Champagne } \\
\hline & & MS & $F$ value & MS & $F$ value \\
\hline Replication & 9 & 2.03 & 1.27 & 0.01 & 0.88 \\
\hline Differential host & 4 & 5.09 & $7.14 * *$ & 0.11 & $9.14 * *$ \\
\hline Residual & 36 & 0.46 & $\ldots$ & 0.08 & $\ldots$ \\
\hline
\end{tabular}

a Values followed by ** are significant at $P \leq 0.01$.
RFs in Zebediela and Champagne populations, respectively. Differential-host tests demonstrated that the citrus nematode populations from Zebediela and Champagne had different RFs. The T. semipenetrans biotype from Zebediela had RFs greater than one in grape, rough lemon, carrizo citrange, and trifoliate orange, whereas the RF in olive was lower than one (Table 2). The RFs obtained with $T$. semipenetrans populations from Champagne were less than one on all rootstocks, whereas the RF on olive was significantly lower than those on other differential-host plants.

Comparisons of number of nematodes per differential host across locations suggested that populations from Zebediela were always reproducing significantly more than those from Champagne (Table $3)$. For instance, the numbers of nematode juveniles from Zebediela were approximately six times more than those from Champagne in grape roots and approximately three times more in the soil.

\section{DISCUSSION}

An RF provides a basic measurement of the nematode reproduction potential and, therefore, gives good indication of the host status of a plant to the nematode under study (18). All RF values above one indicate susceptibility of the host, whereas those below one indicate resistance, which is expressed in terms of the inability of the nematode to develop and reproduce in the host plant. Using nematode reaction on differential host, olive was consistently

Table 2. Mean comparison for reproductive factors of Tylenchulus semipenetrans from two citrus-producing regions of South Africa within roots and soil of differential hosts $(n=10)$

\begin{tabular}{|c|c|c|c|c|c|c|c|c|}
\hline \multirow[b]{3}{*}{ Differential host } & \multicolumn{4}{|c|}{ Zebediela } & \multicolumn{4}{|c|}{ Champagne } \\
\hline & \multicolumn{2}{|c|}{ Total no. of nematodes } & \multirow[b]{2}{*}{ Final $^{\mathbf{a}}$} & \multirow[b]{2}{*}{$\mathbf{R F}^{\mathbf{b}}$} & \multicolumn{2}{|c|}{ Total no. of nematodes } & \multirow[b]{2}{*}{ Final $^{\mathbf{a}}$} & \multirow[b]{2}{*}{$\mathbf{R F}^{\mathbf{c}}$} \\
\hline & Root & Soil & & & Root & Soil & & \\
\hline Grape & 4,935 & 10,786 & 15,721 & 1.57 & 3,060 & 14,434 & 17,494 & 0.44 \\
\hline Carrizo citrange & 1,096 & 9,038 & 10,134 & 1.01 & 3,194 & 15,109 & 18,303 & 0.46 \\
\hline Rough lemon & 4,994 & 10,046 & 14,007 & 1.50 & 8,802 & 15,008 & 23,810 & 0.59 \\
\hline Olive & 1,554 & 6,059 & 7,613 & 0.76 & 423 & 6,966 & 7,389 & 0.19 \\
\hline Trifoliate orange & 2,071 & 13,362 & 15,433 & 1.54 & 1,312 & 14,246 & 15,558 & 0.39 \\
\hline $\mathrm{LSD}_{0.05}{ }^{\mathrm{d}}$ & 2,064 & 3,352 & $\ldots$ & 0.39 & 880 & 4,020 & $\ldots$ & 0.10 \\
\hline
\end{tabular}

${ }^{\text {a }}$ Final population $=$ nematode number in total root and soil.

${ }^{b}$ Reproductive factor $(\mathrm{RF})=$ final population $(\mathrm{Pf}) /$ initial population $(\mathrm{Pi}=10,000)$.

${ }^{c} \mathrm{RF}=\mathrm{Pf} / \mathrm{Pi}(=40,000)$

${ }^{\mathrm{d}}$ Least significant difference at $P \leq 0.05$.

Table 3. Comparisons of populations from two locations on mean population density of Tylenchulus semipenetrans within roots and soil of differential hosts 4 months after inoculation ${ }^{\mathrm{a}}$

\begin{tabular}{|c|c|c|c|c|c|c|}
\hline \multirow[b]{2}{*}{ Differential hosts } & \multicolumn{3}{|c|}{ Nematode/total root } & \multicolumn{3}{|c|}{ Nematode/total soil } \\
\hline & Zebediela & Champagne & $t$ Value & Zebediela & Champagne & $t$ Value \\
\hline Grape & 4,935 & 765 & $3.91 * *$ & 10,786 & 3,594 & $7.24 * *$ \\
\hline Carrizo citrange & 1,096 & 333 & $4.38 * *$ & 9,038 & 3,542 & $7.37 * *$ \\
\hline Rough lemon & 3,961 & 574 & $3.09 *$ & 10,046 & 3,752 & $5.41 * *$ \\
\hline Olive & 1,554 & 106 & $4.88 * *$ & 6,059 & 1,742 & $3.38 * *$ \\
\hline Trifoliate orange & 2,071 & 328 & $1.60^{\mathrm{ns}}$ & 13,362 & 3,562 & $4.34 * *$ \\
\hline
\end{tabular}

${ }^{a}$ Initial population ( $\mathrm{Pi}$; number of nematodes) for Champagne was 40,000 second-stage juveniles. Thus, values were standardized to Pi $=10,000$ for the purpose of comparison against Zebediela. Values followed by $*$ and $* *$ are significant at 5 and $1 \%$ probability levels, respectively; ns $=$ nonsignificant difference. 
resistant to $T$. semipenetrans populations used in this study, whereas other hosts, including trifoliate orange, were susceptible.

Generally, T. semipenetrans biotypes are distinguishable from their RFs on (i) citrus and their relatives such as carrizo citrange, (ii) trifoliate orange, and (iii) olive. The citrus nematode biotype reproduces on citrus, its relatives, and olive, whereas the mediterranean biotype does not reproduce on trifoliate orange and olive $(7,9,17)$. Poncirus biotype reproduces on trifoliate orange but not olive $(9,12)$. On this basis, the $T$. semipenetrans biotype in this study appears to be poncirus biotype, because it reproduced on $P$. trifoliate but not olive.

In the Champagne population, the RFs on all differential hosts were less than one, suggesting that the contributing factor was the same in all treatments. A model proposed by Seinhorst (15) suggested that maximum rates of nematode reproduction could be achieved only before equilibrium (E) point $(\mathrm{Pi}=\mathrm{Pf})$. Generally, before $\mathrm{E}$, RFs are higher than one if the host is suitable whereas, after E, the RFs are lower than one. Based on this model, it appears that, for the Champagne population, the inoculation level of 40,000 nematodes per plant was higher than the $\mathrm{E}$ point for $T$. semipenetrans on the tested hosts, whereas that of 10,000 nematodes for Zebediela was less than the E. Despite the discrepancy in $\mathrm{Pi}$ in the two independent experiments, results in Champagne indicated that all hosts except olive were suitable for the reproduction of $T$. semipenetrans.

In a survey for the $T$. semipenetrans from various fruit orchards in the Western Cape Province, Republic of South Africa, $T$. semipenetrans was detected in grape, persimmon, and various citrus orchards but not in olive orchards (P. W. Mashela, unpublished). The present investigation suggested that the biotype of $T$. semipenetrans from Zebediela and Champagne, Republic of South Africa, is poncirus. Further studies with molecular markers are needed to validate results of the differential-host test, and to determine the distribution and prevalence of the poncirus biotype in citrus-producing regions of South Africa. The identification of the T. semipenetrans biotype in South Africa will be helpful to recommend the most suitable rootstock and further utilization in citrus improvement programs.

\section{ACKNOWLEDGMENTS}

Financial support was provided by the National Research Foundation and the Land Bank of South Africa. We thank E. Mathebula for technical assistance during the experiment.

\section{LITERATURE CITED}

1. Baines, R. C., Cameron, J. W., and Soost, R. K. 1974. Four biotypes of Tylenchulus semipenetrans in California identified and their importance in the development of resistant rootstocks. J. Nematol. 6:63-66.

2. Cohn, E. 1976. Reports on investigations on nematode of citrus and subtropical fruit crops in South Africa. Report Citrus Subtropical Fruit Resource Institute, Nelspruit.

3. Coolen, W. A. 1979. Methods for extraction of Meloidogyne spp. and other nematodes from roots and soil. Pages 317-329 in: Root-Knot Nematodes (Meloidogyne species) Systematics, Biology and Control. F. Lamberti and C. E. Taylor, eds. Academic Press, New York.

4. De Villiers, E. A., and Milne, D. L. 1976. Sitrusaalwurm. Tylenchulus semipenetrans Cobb. Boerdery Suid-Afrika H. 5/1976.

5. Duncan, L. W. 2005. Nematode parasites of citrus. Pages 437-466 in: Plant Parasitic Nematodes in Subtropical and Tropical Agriculture. M. Luc, R. A. Sikora, and J. Bridge, eds. CABI Publishing, Wallingford, UK.

6. Duncan, L. W., Inserra, R. N., O'Bannon, J. H., and El-Morshedy, M. M. 1994. Reproduc- tion of a Florida population of Tylenchulus semipenetrans on resistant citrus rootstocks. Plant Dis. 78:1067-1071.

7. Gottlieb, Y., Cohn, E., and Spiegel-Roy, P. 1986. Biotypes of the citrus nematode (Tylenchulus semipenetrans Cobb.) in Israel. Phytoparasitica 14:193-198.

8. Hussey, R. S., and Barker, K. R. 1973. A comparison of methods of collecting inocula of Meloidogyne spp. including a new technique. Plant Dis. Rep. 57:1025-1028.

9. Inserra, R. N., Volvas, N., and O'Bannon, J. H. 1980. A classification of Tylenchulus semipenetrans biotypes. J. Nematol. 12:283-287.

10. Lo Giudice, V., and R. N. Inserra. 1980. Reaction of citrus and noncitrus rootstocks to $T y$ lenchulus semipenetrans. Nematol. Mediterr. 8:103-105.

11. O'Bannon, J. H., Chew, V., and Tomerlin, A. T. 1977. Comparison of five populations of $T y$ lenchulus semipenetrans to Citrus, Poncirus and their hybrids. J. Nematol. 9:162-165.

12. O'Bannon, J. H., and Ford, H. W. 1977. Resistance in citrus rootstocks to Radopholus similis and Tylenchulus semipenetrans (Nematoda) Proc. Int. Soc. Citricult. 2:544-549.

13. Rabe, E., and Von Broembsen, L. A. 1991. Production Guidelines for Export citrus. Vol. 1, Citriculture-Establishment. Co-op Citrus Exchange, Technical Division, S.A.

14. Rodriguez-Kabana, R., and Pope, M. H. 1981. A simple incubation method for the extraction of nematodes from soil. Nematropica 11:175186.

15. Seinhorst, J. W. 1966. The relationships between population increase and population densities in plant-parasitic nematodes. 1. Introduction and migratory nematodes. Nematologica 12:157-169.

16. Stokes, D. E. 1969. Andropogon rhizomatus parasitized by a strain of Tylenchulus semipenetrans not parasitic to four citrus rootstocks. Plant Dis. Rep. 52:882-885.

17. Verdejo-Lucas, S. 1992. On the occurrence of the "Mediterranean biotype" of Tylenchulus semipenetrans in Spain. Fund. Appl. Nematol. 15:475-477.

18. Windham, G. L., and Williams, W. P. 1988. Reproduction of Meloidogyne javanica on corn hybrids and inbreds. Ann. Appl. Nematol. 2:25-28. 